\title{
Avaliação dos aspectos psicossociais do trabalho e estresse ocupacional nas Estratégias de Saúde da Família de Santa Cruz do Sul, RS.
}

\author{
Vieira, A.R.; Machado, K.C.; Mahl, G.H.; Moreira, I.; Duro, L.; Horta, J.A.; \\ Jackes, C.S.;
}

Apresentador: Alexandra Rech Vieira

\section{Resumo}

Introdução: O trabalho é considerado um meio de inserção do indivíduo na comunidade e, além de reforçar sua identidade, lhe assegura subsídios para o sustento próprio e de sua família. Os fatores psicossociais do trabalho influenciam a satisfação pessoal e profissional, uma vez que estão intimamente relacionados à organização laboral e às capacidades do trabalhador. Nessa perspectiva, o estresse ocupacional surge como um recurso adaptativo para o enfrentamento das imposições laborais fazendo com que o trabalho seja uma importante fonte de saúde mental, física e de crescimento ou, em situações adversas, ser nocivo e adquirir um caráter patológico. Método: Trata-se de um estudo transversal e quantitativo. A população foi composta por 83 profissionais, entre médicos, enfermeiros, técnicos/auxiliares de enfermagem e agentes comunitários de saúde que atuam nas 11 Estratégias de Saúde da Família (ESF) do município de Santa Cruz do Sul- RS. Os trabalhadores responderam a um questionário autoaplicável e anônimo, englobando aspectos sociodemográficos, ocupacionais e questões pertencentes à Job Stress Scale (JSS) para avaliação de aspectos psicossociais do trabalho de acordo como o Modelo DemandaControle de Karasek. Os dados foram coletados em junho a setembro do ano de 2013. O estudo foi aprovado pelo Comitê de Ética em Pesquisa (CEP) da UNISC, sob CAAE $n^{\circ}$ 06706912.3.0000.5343 e pela coordenação da Secretaria de Saúde do município. Resultados: Observou-se que 30,1\% dos trabalhadores avaliados encontravam-se alocados em serviços de baixo controle e alta demanda, portanto, considerados altamente expostos ao estresse ocupacional e estando mais suscetíveis ao adoecimento no âmbito laboral. Além disso, 38,5\% dos profissionais entrevistados foram considerados em posição intermediária ao estresse ocupacional, uma parcela relevante, já que esses profissionais poderão tornar-se grupo de alta exposição. Conclusão: Em suma, verificou-se que grande parte dos profissionais que atuam nas ESF de Santa Cruz do Sul estão expostos a estresse ocupacional e, assim, em risco de adoecimento físico e psíquico. Dessa forma, são necessárias ações que enfoquem melhorias nas condições de trabalho/ambiente laboral, bem como o cuidado da saúde mental dos profissionais. Sugerese a criação espaços de reflexões, escuta e apoio a esses trabalhadores.

\section{Referência:}

Vieira, A.R.; Machado, K.C.; Mahl, G.H.; Moreira, I.; Duro, L.; Horta, J.A.; Jackes, C.S.;. Avaliação dos aspectos psicossociais do trabalho e estresse ocupacional nas Estratégias de Saúde da Família de Santa Cruz do Sul, RS.. In: II Congresso

Brasileiro de Medicina Hospitalar - II CBMH [= Blucher Medical Proceedings, vol.1, num.5] São Paulo: Editora Blucher, 2014. p.73

DOI 10.5151/medpro-II-cbmh-070 